\title{
Accuracy of the VITEK 2 system for a rapid and direct identification and susceptibility testing of Gram- negative rods and Gram-positive cocci in blood samples
}

N.A. Nimer, R.J. Al-Saa'da ${ }^{2}$ and O. Abuelaish ${ }^{3}$

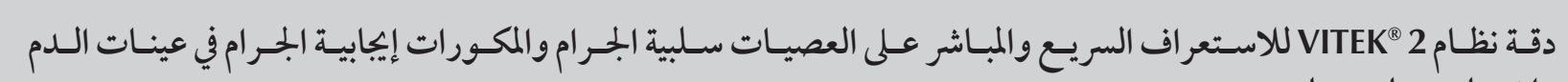

$$
\begin{aligned}
& \text { واختبـار حساسـيتها }
\end{aligned}
$$

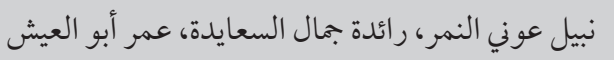

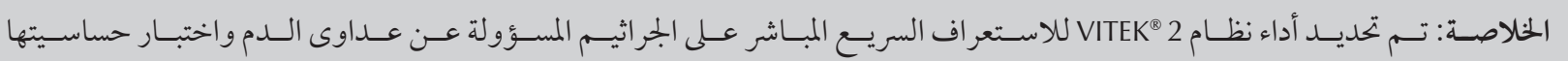

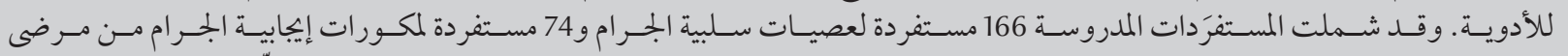

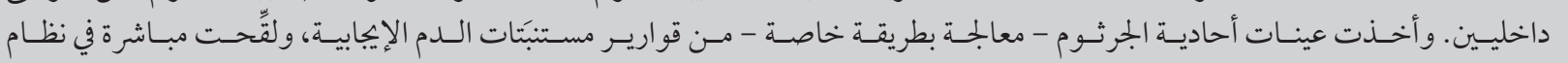

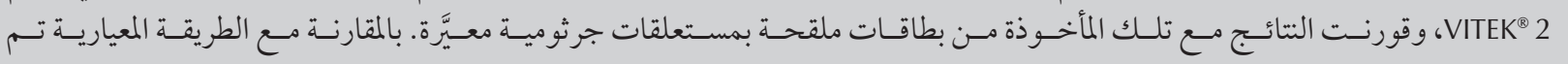

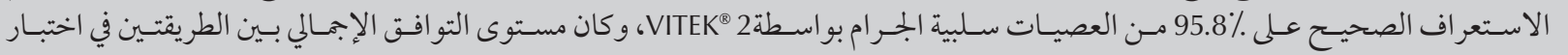

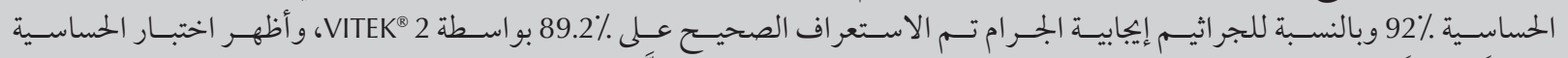

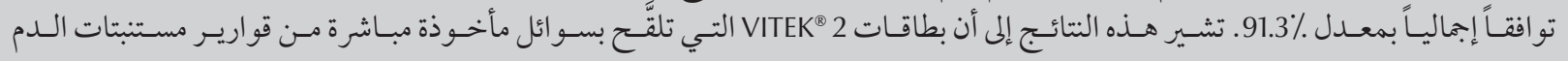

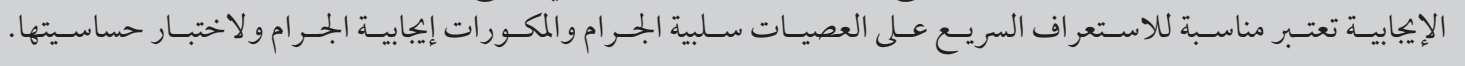

ABSTRACT The performance of the VITEK 2 system for direct rapid identification and antimicrobial susceptibility testing of the bacteria responsible for blood infections was determined. The isolates studied included 166 Gram-negative rods and $74 \mathrm{Gram}$-positive cocci from inpatients. Specially treated monomicrobial samples from positive blood culture bottles were directly inoculated into the VITEK 2 system and the results were compared with those from cards inoculated with standardized bacterial suspensions. Compared with the standard method, 95.8\% of Gram-negative rods were correctly identified by VITEK 2 and the overall level of agreement between the two methods in susceptibility testing was $92.0 \%$. For Gram-positive bacteria, $89.2 \%$ were correctly identified by VITEK 2 and susceptibility testing revealed an overall agreement rate of $91.3 \%$. These results suggest that VITEK 2 cards inoculated with fluids sampled directly from positive blood culture bottles are suitable for speedy identification and susceptibility testing of Gram-negative bacilli and Gram-positive cocci.

Précision du système VITEK 2 pour une identification et un test de sensibilité directs et rapides des bâtonnets à gram négatif et des cocci à gram positif dans des échantillons sanguins

RÉSUMÉ La performance du système VITEK 2 pour une identification et un test de sensibilité aux antimicrobiens rapides et directs des bactéries responsables d'infections sanguines a été mesurée. Les isolats étudiés concernaient 166 bâtonnets à gram négatif et 74 cocci à gram positif prélevés sur des patients hospitalisés. Des échantillons monomicrobiens issus de flacons d'hémoculture positifs ayant été soumis à un traitement spécial ont été directement inoculés dans le système VITEK 2 et les résultats ont été comparés avec ceux issus de cartes inoculées à l'aide de suspensions bactériennes standards. Par comparaison avec la méthode standard, 95,8\% des bâtonnets à gram négatif ont été correctement identifiés par VITEK 2 et le niveau de concordance global entre les deux méthodes en matière de test de sensibilité était de 92,0\%. Pour les bactéries à gram positif, 89,2\% ont été correctement identifiées par VITEK 2 et le test de sensibilité a révélé un taux de concordance de $91,3 \%$. Ces résultats suggèrent que les cartes VITEK 2 inoculées à l'aide de liquides prélevés directement dans des flacons d'hémoculture positifs sont adaptées à une identification et à un test de sensibilité rapides des bacilles à gram négatif et des cocci à gram positif.

${ }^{1}$ Faculty of Pharmacy, Philadelphia University, Amman, Jordan (Correspondence to N.A. Nimer: nabilnimer@hotmail.com). ${ }^{2}$ Princess Iman Research and Laboratory Sciences Centre, Royal Medical Services, Amman, Jordan. ${ }^{3}$ King Hussein Medical Center, Royal Medical Services, Amman, Jordan. Received: 03/10/15; accepted: 20/01/16 


\section{Introduction}

Bacteraemia is an invasion of the bloodstream by viable bacteria that can develop into a serious and deadly infection. For critically ill patients, bloodstream infections are a major cause of morbidity and mortality despite significant advances in supportive care and the availability of effective antimicrobial therapy $(1,2)$. The bloodstream can be infected by microorganisms via various channels, such as surgical and dental procedures, teeth brushing, insertions of catheters, urinary tract or gastrointestinal infections and intravenous drug use $(3,4)$.

Different types of bacteria are responsible for bloodstream infections. Gram-negative bacteria were common in the 1970s, especially in hospitalized patients, but currently Gram-positive bacteria are the predominant causative agents (5). Gram-negative bacteria that are frequently associated with blood infections include Enterobacteriaceae such as Escherichia coli, Klebsiella pneumoniae and Pseudomonas aeruginosa (6). Among Gram-positive bacterial infections, Staphylococcus aureus and coagulase-negative staphylococci are the predominant causative agents, but other bacteria, such as enterococci and streptococci can also be associated (7). Minor bloodstream infections can be managed by the immune system, but severe infections need to be treated with antibiotics. The increasing rate of multidrug-resistant bacteria associated with bacteraemia, however, is raising serious concerns (6).

In order to determine the best treatment for a patient, it is important to carry out proper identification and susceptibility testing of the causative agents. However, the rapidity with which the identification and susceptibility testing are done is critical for a positive outcome for the patient and hence for decreasing the mortality and morbidity rate associated with such infections. Various methods have been used for the detection and identification of microorganisms in blood. The conventional method commonly used in clinical laboratories involves inoculation onto agar media and overnight incubation of fluids from blood culture bottles, followed by recovery of a satisfactory bacterial inoculum size to prepare standard suspensions for identification (biochemical or immunological tests) and antimicrobial susceptibility testing (8). However, this method is time-consuming as it requires 48-72 $\mathrm{h}$ (more for slow-growing bacteria) for the results to be obtained, including 4-24 h of incubation time for blood cultures and an additional $24-48 \mathrm{~h}$ for biochemical or immunological tests for identification and susceptibility testing (8). These delays have prompted the development of several automated and rapid identification and susceptibility testing systems that are used by some clinical laboratories. These include the VITEK 2 automated identification (ID) and antibiotic susceptibility testing (AST) systems, the MicroScan ID and AST panels, fluorescence in situ hybridization (FISH) and polymerase chain reaction (PCR) analyses (8-12).

The VITEK system used in the present study was developed by bioMérieux as an automated system for identification and antimicrobial susceptibility testing and was later improved into the VITEK 2 system. The improved version automates all mandatory steps for identification and antimicrobial susceptibility testing after a standardized inoculum has been loaded into the system (13). The samples are read every $15 \mathrm{~min}$. by a kinetic analysis of fluorescence, turbidity and colorimetric signals. The results are available within $3 \mathrm{~h}$ for identification and $2.5-18 \mathrm{~h}$ for susceptibility testing.

Various studies have evaluated the performance of the VITEK 2 system for identification of Gram-negative and -positive bacteria associated with bacteraemia $(13,14)$, but the results vary across studies. This variability does not allow clear and definite conclusions about the performance of the system for both identification and susceptibility testing. In the present study in a laboratory in Jordan, both methodologies were applied for the identification and susceptibility testing of Gram-negative rods and Gram-positive cocci and the results were compared to evaluate the performance of the VITEK 2 system.

\section{Methods}

This study was carried out using bacterial isolates collected from January to December 2012 from specimens at the Princess Iman Research and Laboratory Sciences Centre of the Royal Medical Services in Amman, Jordan.

\section{Detection of microorganisms in blood samples}

The presence of microorganisms in blood samples from hospitalized patients was detected using the $\mathrm{BacT} /$ ALERT microbial detection system (bioMérieux). Samples were inoculated into BacT/ALERT standard aerobic and standard anaerobic blood culture bottles, which were transferred to the BACTEC $^{\mathrm{m}} 9240$ blood culture system, software version V4.70A (Becton Dickinson) for monitoring bacterial growth. Positive blood cultures containing Gram-negative rods and Gram-positive cocci that appeared monomicrobial in the Gram stain were included in the study. In total, 233 positive aerobic blood cultures were analysed, including 166 cultures with Gram-negative bacilli and 74 with Gram-positive cocci.

\section{Direct identification of bacteria using the VITEK 2 ID system}

The bacteria were directly identified using samples from the blood culture bottles that were incubated for 4-24 $\mathrm{h}$ at $35^{\circ} \mathrm{C}$. From each bottle, $3 \mathrm{~mL}$ or $9 \mathrm{~mL}$ fluid (for Gram-positive cocci) were sampled and first centrifuged at $150 \times \mathrm{g}$ for $10 \mathrm{~min}$. in order to isolate the blood cells (in the pellet). Then 
the bacteria cells were harvested by centrifuging (at $1000 \times \mathrm{g}$ for $10 \mathrm{~min}$.) a mixture of $2 \mathrm{~mL}$ supernatant with $1 \mathrm{~mL}$ of $0.45 \%$ saline to eliminate residual red blood cells by lysis. A bacterial suspension was prepared by mixing the pellet with $0.45 \%$ saline to obtain a concentration of $0.5-0.63$ McFarland units using the VITEK DensiCHEK ${ }^{\text {w }}$ colorimeter (bioMérieux). When no bacterial pellet was observed after the second centrifugation for Gram-positive bacteria, 1.5 $\mathrm{mL}$ of $0.45 \%$ saline and $3 \mathrm{~mL}$ of brainheart infusion were added and the tube incubated under shaking at $37^{\circ} \mathrm{C}$ for 2 $\mathrm{h}$ to induce a better growth.

The suspensions $(2 \mathrm{~mL})$ were automatically loaded into the VITEK 2 ID system (bioMérieux), using the GNB and GPC cards for identification of Gram-negative rods and Gram-positive cocci respectively and the version 2.01 release software. The cards were read by kinetic fluorescence measurement and the results reported within $3 \mathrm{~h}$.

\section{Direct testing of antimicrobial susceptibility of bacteria using the VITEK 2 AST system}

For the susceptibility testing, only bacteria correctly identified with the VITEK 2 ID system were included in the experiments. Then $2 \mathrm{~mL}$ samples of each suspension were prepared as described above and were automatically loaded into the VITEK 2 AST system (bioMérieux) using the GN04 and P526 cards for susceptibility testing of Gram-negative rods and for Grampositive cocci respectively and the 2.01 release software. The cards were read by kinetic fluorescence measurement and the results reported within $2.5-16.25 \mathrm{~h}$.

A total of 10 antimicrobials were screened for Gram-negative rods: ampicillin, aztreonam, cefepime, ceftazidime, ceftriaxone, imipenem, ciprofloxacin, gentamicin, amikacin, and trimethoprim-sulfamethoxazole. For Grampositive cocci, the susceptibility against 9 antimicrobials was investigated: ciprofloxacin, clindamycin, erythromycin, gentamicin, oxacillin, penicillin, trimethoprim-sulfamethoxazole, teicoplanin and vancomycin.

\section{Identification \& susceptibility testing of bacteria by the standard method}

To determine the accuracy of the direct identification and susceptibility testing of bacteria in the blood samples, the microorganisms were also screened by a standard method. For this purpose, blood and chocolate agar plates were inoculated with about $0.1 \mathrm{~mL}$ of culture liquid from a blood culture bottle, followed by an overnight incubation at $35^{\circ} \mathrm{C}$ in $5 \%$ carbon dioxide. The bacterial suspension for each isolate was then prepared and the turbidity adjusted to match that of a McFarland $0.5-0.63$ standard in $0.45 \%$ sterile sodium chloride solution. The suspensions $(2 \mathrm{~mL})$ were loaded into the appropriate VITEK 2 ID and AST cards as described above.

For comparison with the standard method using the VITEK 2 ID cards and for bacteria that were not identified by that method, analytical profile index (API) identification systems (bioMérieux) were used. Enterobacteriaceae were identified with API 20E, non-fermenters with API 20NE, Enterococcus spp. and Streptococcus spp. with API Strep, Micrococcus spp. and Staphylococcus spp. with API Staph.

For the susceptibility testing, the bacteria were additionally tested against the antimicrobials mentioned above using the broth microdilution method, according to guidelines and breakpoints set by the Clinical and Laboratory Standards Institute. The inoculum concentration was 105 colony-forming units/mL and an appropriate broth was used for each type of bacteria.

\section{Quality control}

For all experiments performed with both VITEK 2 ID and VITEK 2 AST cards, E. coli (ATCC) 25922, P. aeruginosa ATCC 27853, and Staph. aureus
ATCC 29213 were used as reference strains for quality controls.

\section{Analysis of the identification and sus- ceptibility testing of bacteria}

To screen the accuracy of the direct identification and susceptibility testing of bacteria in the blood samples, the VITEK 2 standard and VITEK 2 direct methods were compared. For the bacteria identification, the results of the VITEK 2 standard method were used as the reference, except in a few cases where the API system results were necessary to provide a definitive identification. Only bacteria that were correctly identified by the standard method were included in the comparison. The results from the direct identification method were reported as: correctly identified; misidentified; or not identified. In the VITEK 2 ID system, K. pneumoniae subsp. pneumoniae (planticola/terrigena) and $K$. pneumoniae subsp. ozaenae were considered identical and reported as $K$. pneumoniae.

For the susceptibility testing, the results of the direct method were classified into 4 groups: category agreement (complete agreement between the two methods); minor discrepancy (susceptible or resistant by the direct method and intermediate by the standard method or vice versa); major discrepancy (resistant by the direct method but sensitive by the standard method); and very major discrepancy (sensitive by the direct method but resistant by the standard method).

\section{Results}

\section{Identification of Gram- negative rods \& Gram-positive cocci by the standard method}

By the standard method, 166 Gramnegative bacteria were identified and tested (Table 1). These included 113 isolates of Enterobacteriaceae and 53 non-fermenting bacteria. Enterobacteriaceae species included E. coli, Ent. faecalis, Ent. cloacae, K. pneumonia, K. oxytoca 


\begin{tabular}{|c|c|c|c|c|c|c|c|c|c|}
\hline & \multirow{2}{*}{$\begin{array}{c}\text { Isolate } \\
\text { tested } \\
\text { No. }\end{array}$} & \multicolumn{2}{|c|}{$\begin{array}{l}\text { Correctly } \\
\text { identified }\end{array}$} & \multicolumn{2}{|c|}{ VNGNB } & \multicolumn{2}{|c|}{ Not identified } & \multicolumn{2}{|c|}{ Misidentified } \\
\hline & & No. & $\%$ & No. & $\%$ & No. & $\%$ & No. & $\%$ \\
\hline \multicolumn{10}{|l|}{ Enterobacteriaceae } \\
\hline Escherichia coli & 38 & 38 & 100.0 & 0 & 0.0 & 0 & 0.0 & 0 & 0.0 \\
\hline Enterobacter faecalis & 14 & 13 & 92.9 & 0 & 0.0 & 0 & 0.0 & 1 & 7.7 \\
\hline Enterobacter cloacae & 3 & 3 & 100.0 & 0 & 0.0 & 0 & 0.0 & 0 & 0.0 \\
\hline Klebsiella pneumoniae & 46 & 44 & 95.7 & 0 & 0.0 & 0 & 0.0 & 2 & 4.5 \\
\hline Klebsiella oxytoca & 1 & 1 & 100.0 & 0 & 0.0 & 0 & 0.0 & 0 & 0.0 \\
\hline Salmonella spp. & 9 & 9 & 100.0 & 0 & 0.0 & 0 & 0.0 & 0 & 0.0 \\
\hline Aeromonas spp. & 2 & 2 & 100.0 & 0 & 0.0 & 0 & 0.0 & 0 & 0.0 \\
\hline Total & 113 & 110 & 97.3 & 0 & 0.0 & 0 & 0.0 & 3 & 2.7 \\
\hline \multicolumn{10}{|l|}{ Non-fermenters } \\
\hline Acinetobacter baumannii & 42 & 40 & 95.2 & 2 & 4.8 & 0 & 0.0 & 0 & 0.0 \\
\hline Chryseobacterium indologenes & 1 & 1 & 100.0 & 0 & 0.0 & 0 & 0.0 & 0 & 0.0 \\
\hline Pseudomonas aeruginosa & 10 & 8 & 80.0 & 2 & 20 & 0 & 0.0 & 0 & 0.0 \\
\hline Total & 53 & 49 & 92.5 & 4 & 7.5 & 0 & 0.0 & 0 & 0.0 \\
\hline All types & 166 & 159 & 95.8 & 4 & 2.4 & 0 & 0.0 & 3 & 1.8 \\
\hline
\end{tabular}

$V N G N B=$ various non-fermenting Gram-negative bacilli.

and isolates of the genus Salmonella and Aeromonas. The non-fermenters included Acinetobacter baumannii, Chryseobacterium indologenes and $P$. aeruginosa. A total of 74 Gram-positive cocci were identified and tested (Table 2), including 14 isolates of the genus Enterococcus (Ent. faecalis and Ent. faecium), 45 of the genus Staphylococcus (Staph. aureus, Staph. epidermidis, Staph. haemolyticus and coagulase-negative staphylococci ), 12 of the genus Streptococcus (Strep. agalactiae, group D streptococci and Strep. pneumoniae) and 3 of the genus Micrococcus.

\section{Direct identification of Gram- negative rods using the VITEK 2 ID-GNB card}

The Gram-negative bacteria identified by the standard method were also investigated by a direct inoculation of culture fluids from positive blood cultures into VITEK 2 ID- GNB cards. Comparing with the standard method, the analysis revealed that most bacteria were successfully identified. As seen in Table 1, among the 166
Gram-negative bacteria investigated, $95.8 \%(159 / 166)$ showed concordant results with the standard method, $2.4 \%(4 / 166)$ were classified as various non-fermenting Gram-negative bacilli and $1.8 \%(3 / 166)$ were misidentified. For bacteria of the family Enterobacteriaceae, 97.3\% (110/113) were correctly identified and $2.7 \%$ (3/113) were misidentified ( 1 isolate of Ent. faecalis and 2 of K. pneumonia). Enterobacter faecalis was misidentified as Kleibseilla sp. and K. pneumonia as Enterococcus spp. Of the non-fermenter bacteria $92.5 \%$ (49/53) were correctly identified and $7.5 \%$ were reported as various non-fermenting Gram-negative bacilli ( 2 isolates of A. baumannii and 2 of P. aeruginosa).

\section{Direct identification of Gram- positive cocci using the VITEK 2 ID-GPC card}

The Gram-positive cocci identified by the standard method were also investigated by a direct inoculation of culture fluids from positive blood cultures into VITEK 2 ID-GPC cards. Comparing with the standard method (Table 2), the comparative analysis revealed that $89.2 \%(66 / 74)$ of the bacteria were correctly identified, $6.8 \%(5 / 74)$ not identified and 4.1\% (3/74) misidentified. It was noticed that although the majority of isolates were correctly identified, the percentage success was $6.6 \%$ less than the success rate obtained for the Gram-negative bacteria. The bacteria that were not identified by the direct method included 2 isolates of Staph. aureus and 1 each for Ent. faecalis, group D streptococci and Strep. pneumoniae. Only 3 isolates of coagulase-negative staphylococci were misidentified: 1 as Corynebacterium spp. and 2 as Micrococcus spp. With regards to each group of cocci, $92.9 \%$ of enterococci $(13 / 14)$ were successfully identified and $7.1 \%$ were not identified. For the Staphylococcus spp., $88.9 \%$ (40/45) were correctly identified, $4.4 \%$ (2/45) not identified and $6.7 \%$ misidentified $(3 / 45)$. For the Streptococcus spp., $83.3 \%(10 / 12)$ were correctly identified and $16.7 \%$ $(2 / 12)$ not identified. All 3 isolates 


\begin{tabular}{|c|c|c|c|c|c|c|c|}
\hline \multirow[t]{2}{*}{ Bacteria } & \multirow{2}{*}{$\begin{array}{c}\text { Isolates } \\
\text { tested } \\
\text { No. }\end{array}$} & \multicolumn{2}{|c|}{ Correctly identified } & \multicolumn{2}{|c|}{ Not identified } & \multicolumn{2}{|c|}{ Misidentified } \\
\hline & & No. & $\%$ & No. & $\%$ & No. & $\%$ \\
\hline \multicolumn{8}{|l|}{ Enterococci } \\
\hline Enterococcus faecalis & 11 & 10 & 90.9 & 1 & 9.1 & 0 & 0.0 \\
\hline Enterococcus faecium & 3 & 3 & 100.0 & 0 & 0.0 & 0 & 0.0 \\
\hline Total & 14 & 13 & 92.9 & 1 & 7.1 & 0 & 0.0 \\
\hline Micrococcus spp. & 3 & 3 & 100.0 & 0 & 0.0 & 0 & 0.0 \\
\hline \multicolumn{8}{|l|}{ Staphylococci } \\
\hline Staphylococcus aureus & 31 & 29 & 93.5 & 2 & 6.5 & 0 & 0.0 \\
\hline Staphylococcus epidermidis & 2 & 2 & 100.0 & 0 & 0.0 & 0 & 0.0 \\
\hline Staphylococcus haemolyticus & 4 & 4 & 100.0 & 0 & 0.0 & 0 & 0.0 \\
\hline Coagulase-negative staphylococci & 8 & 5 & 62.5 & 0 & 0.0 & 3 & 37.5 \\
\hline Total & 45 & 40 & 88.9 & 2 & 4.4 & 3 & 6.7 \\
\hline \multicolumn{8}{|l|}{ Streptococci } \\
\hline Streptococcus agalactiae & 2 & 2 & 100.0 & 0 & 0.0 & 0 & 0.0 \\
\hline Group D streptococci & 4 & 3 & 75.0 & 1 & 25.0 & 0 & 0.0 \\
\hline Streptococcus pneumoniae & 6 & 5 & 83.3 & 1 & 16.7 & 0 & 0.0 \\
\hline Total & 12 & 10 & 83.3 & 2 & 16.7 & 0 & 0.0 \\
\hline All types & 74 & 66 & 89.2 & 5 & 6.8 & 3 & 4.1 \\
\hline
\end{tabular}

belonging to the genus Micrococcus were correctly identified.

\section{Susceptibility testing of Gram-negative bacteria to antimicrobials using the VITEK 2 AST-GN04 card}

For the susceptibility testing, only correctly identified bacteria were considered $(n=159)$. The results obtained by the standard method were compared with those obtained with the direct method (Table 3). The 159 isolates were evaluated for their susceptibility to 10 antimicrobials, resulting in a total of 1590 isolate-antimicrobial compound combinations. The overall level of agreement between the two methods was $92.0 \%$. The highest level of agreement was obtained for amikacin (98.7\%) and the lowest for ampicillin, ceftazidime and ceftriaxone (88.0\%). The overall disagreement rate was $8.6 \%$ including $4.9 \%$ minor discrepancies, $2.9 \%$ major discrepancies and $0.8 \%$ very major discrepancies. Regarding individual antimicrobials, the highest rate of discrepancy was seen for ampicillin, ceftazidime and ceftriaxone.

\section{Susceptibility testing of Gram-positive bacteria to antimicrobials using the VITEK 2 AST-P526 card}

Similarly to the susceptibility testing of the Gram-negative bacteria, only successfully identified bacteria were considered $(n=67)$. The results obtained by the standard method were compared with those obtained with the direct method (Table 4). The 66 isolates were evaluated for their susceptibility to 9 antimicrobials resulting in a total of 603 isolate-antimicrobial compound combinations. The overall level of agreement between the two methods was $91.3 \%$. The highest level of agreement was obtained for vancomycin (100\%) and trimethoprim-sulfamethoxazole (97.0\%) and the lowest rate of agreement was observed for clindamycin (82.0\%). The overall disagreement rate was $8.6 \%$, including $4.8 \%$ minor discrepancies, $2.8 \%$ major discrepancies and $1.0 \%$ very major discrepancies.
Regarding individual antimicrobials, the highest rate of discrepancy was seen for clindamycin, with mainly minor and major discrepancies. Very major discrepancies were only observed for gentamicin, oxacillin and erythromycin.

\section{Discussion}

The present study revealed that the accuracy of the VITEK 2 system for a direct identification and susceptibility testing in blood cultures of Grampositive rods and Gram-negative cocci varied according to the type and species of bacteria as well as the antimicrobial screened.

For both types of bacteria, the overall high level of concordance (95.8\% and $89.2 \%$ ) between the identification results obtained with the standard and direct methods suggest that the VITEK 2 ID system is a suitable tool for a direct and rapid identification of species of bacteria contained in blood cultures. Similar results were obtained 


\begin{tabular}{|c|c|c|c|c|c|c|c|c|}
\hline \multirow[t]{2}{*}{ Variable } & \multicolumn{2}{|c|}{$\begin{array}{l}\text { Category } \\
\text { agreement }\end{array}$} & \multicolumn{2}{|c|}{ Minor discrepancy } & \multicolumn{2}{|c|}{ Major discrepancy } & \multicolumn{2}{|c|}{$\begin{array}{l}\text { Very major } \\
\text { discrepancy }\end{array}$} \\
\hline & No. & $\%$ & No. & $\%$ & No. & $\%$ & No. & $\%$ \\
\hline \multicolumn{9}{|l|}{ Antimicrobials ( $n=159$ isolates tested) } \\
\hline Ampicillin & 140 & 88.0 & 7 & - & 7 & - & 5 & - \\
\hline Aztreonam & 151 & 95.0 & 4 & - & 4 & - & 0 & - \\
\hline Ceftazidime & 140 & 88.0 & 12 & - & 7 & - & 0 & - \\
\hline Ceftriaxone & 140 & 88.0 & 10 & - & 5 & - & 4 & - \\
\hline Cefepime & 148 & 93.0 & 3 & - & 5 & - & 3 & - \\
\hline Imipenem & 150 & 94.3 & 7 & - & 2 & - & 0 & - \\
\hline Ciprofloxacin & 143 & 89.9 & 13 & - & 3 & - & 0 & - \\
\hline Gentamicin & 151 & 95.0 & 6 & - & 2 & - & 0 & - \\
\hline Amikacin & 157 & 98.7 & 2 & - & 0 & - & 0 & - \\
\hline Trimethoprim-sulfamethoxazole & 143 & 89.9 & 8 & - & 8 & - & 0 & - \\
\hline $\begin{array}{l}\text { Total ( } n=1590 \text { isolate-antimicrobial } \\
\text { combinations) }\end{array}$ & 1463 & 92.0 & 72 & 4.9 & 43 & 2.9 & 12 & 0.8 \\
\hline
\end{tabular}

by various previous studies in which a high level of correlation between the two methods were observed. For Gram-negative rods, Chen et al. reported a correlation rate of $89.7 \%$ (8), Ling et al. reported a correlation rate of $95 \%$ and (15) Bruins et al. a correlation of $93.0 \%$, (16). For Grampositive cocci, the present study results correlate with those of Ligozzi et al. whereby more than $90 \%$ of Grampositive cocci were identified within 3 $h$ by the VITEK 2 ID system with up to $99 \%$ identification correlation rate for Staph. aureus (17). Lupetti et al. (14) and Funke and Funke-Kissling (18) also reported a rate of $89-97 \%$ correctly identified Gram-positive cocci. However, a study by de Cueto et al. reported a much lower correlation rate of $62 \%$ for Gram-negative bacilli and a complete disagreement $(0 \%)$ for the Gram-positive cocci (14). Chen et al. also reported a correlation rate of $33 \%$ for Gram-positive cocci with 9 and 33 isolates out of 63 not identified and misidentified respectively (8). De Cueto et al. concluded that the VITEK 2 ID cards inoculated directly with positive Bactec 9240 bottle fluids do not provide an acceptable identification for both types of bacteria in comparison with the corresponding cards tested by a standard method (19). Chen et al. recommended the use of the VITEK 2 system for Gramnegative rods but not for Gram-positive cocci (8). De Cueto et al. justified the difference between their results and those of studies with a high correlation rate by a difference in blood cultures, conventional identification systems and techniques for inoculum preparation from the blood culture bottles (19). Some procedures for inoculum preparation may not be appropriate for a complete removal of substances which may interfere with the fluorescent biochemical reactions occurring in the VITEK 2 cards.

In the present study, the level of disagreement between the two identification methods was higher for Gram-positive bacteria than Gramnegative rods. This phenomenon has been previously observed $(8,19)$ and was attributed to the difficulty to obtain sufficient numbers of bacteria to reach the required VITEK 2 McFarland concentration.

Similar to the bacteria identification results, an overall high level of category agreement was observed between the standard method and direct methods for the susceptibility testing of the studied bacteria to antimicrobials. The agreement of up to 92.0\% and $91.3 \%$ for Gram-negative rods and Gram-positive cocci respectively correlate with previous findings in which $80-100 \%$ category agreement was observed $(8,15-17,20)$. The high rate of concordance observed in the current study and some of the earlier reports can be partly attributed to the fact that only correctly identified bacteria were included in the susceptibility testing. In fact, in studies which included unidentified and misidentified microorganisms, a much lower category agreement for Gram-negative rods (50\%) and Gram-positive cocci (38\%) was observed (19). The present study results demonstrated that the level of category agreement and errors for the susceptibility testing were almost similar for both Gram-negative rods and Gram-positive cocci, thereby contradicting the findings of Chen et al., who found that the rate of errors was much higher for Gram-positive cocci than Gram-negative bacilli (8). The investigation reported here suggests that the VITEK 2 system provides 


\begin{tabular}{|c|c|c|c|c|c|c|c|c|}
\hline \multirow[t]{2}{*}{ Variable } & \multicolumn{2}{|c|}{$\begin{array}{l}\text { Category } \\
\text { agreement }\end{array}$} & \multicolumn{2}{|c|}{ Minor discrepancy } & \multicolumn{2}{|c|}{ Major discrepancy } & \multicolumn{2}{|c|}{$\begin{array}{l}\text { Very major } \\
\text { discrepancy }\end{array}$} \\
\hline & No. & $\%$ & No. & $\%$ & No. & $\%$ & No. & $\%$ \\
\hline \multicolumn{9}{|l|}{ Antimicrobials ( $n=67$ isolates tested) } \\
\hline Clindamycin & 55 & 82.0 & 8 & - & 4 & - & 0 & - \\
\hline Ciprofloxacin & 57 & 85.0 & 7 & - & 3 & - & 0 & - \\
\hline Erythromycin & 60 & 89.5 & 5 & - & 1 & - & 1 & - \\
\hline Gentamicin & 60 & 89.6 & 4 & - & 0 & - & 3 & - \\
\hline Oxacillin & 61 & 91.0 & 0 & - & 4 & - & 2 & - \\
\hline Penicillin & 63 & 94.0 & 0 & - & 4 & - & 0 & - \\
\hline Trimethoprim-sulfamethoxazole & 65 & 97.0 & 1 & - & 1 & - & 0 & - \\
\hline Teicoplanin & 63 & 94.0 & 4 & - & 0 & - & 0 & - \\
\hline Vancomycin & 67 & 100.0 & 0 & - & 0 & - & 0 & - \\
\hline $\begin{array}{l}\text { Total ( } n=603 \text { isolate-antimicrobial } \\
\text { combinations) }\end{array}$ & 551 & 91.3 & 29 & 4.8 & 17 & 2.8 & 6 & 1.0 \\
\hline
\end{tabular}

accurate susceptibility testing results, since the overall rates of agreement with the standard method were above $90 \%$ and the rates of discrepancies below $3 \%$ for major and $1.5 \%$ for very major discrepancies, as stated in the guidelines for the assessment of the performance of antimicrobial susceptibility tests (21). With regards to the level of agreement for individual antimicrobials, a variation of agreement/ discrepancy is observed from one study to another and this may be related to species or subspecies or strain specificity. Nonetheless, occurrence of very major errors seem to be recurrent when testing the susceptibility to some antimicrobials such as ampicillin for Gram-negative bacilli $(8,19)$. On the other hand, the absence or very low rate of errors for the susceptibility testing of Gram-positive cocci toward vancomycin is common $(8,14,19)$.

Using the VITEK 2 system some bacteria in our study were not identified or were misidentified and various levels of disagreement in the susceptibility testing were found. According to De Cueto et al. and Chen et al. these errors can be related to factors such as the use of non-standardized inoculum size or low concentrations of inoculum and incorrect characterization of polymicrobial cultures as monomicrobial $(8,19)$. The Gram staining commonly used to separate polymicrobial and monomicrobial cultures may sometimes lead to errors. In the present study, only monomicrobial cultures were investigated and standardized inoculum was used. It has been also reported that the slower metabolism of some bacteria such as non-enteric and non-fermenting bacteria as well as coagulase-negative staphylococci can cause more errors in their identification/susceptibility testing using the VITEK 2 system $(13,15,17)$. This is due to the fact that the slow metabolism causes weaker fluorescent biochemical reactions in the VITEK 2 card reaction wells (15).

The results of the study reported here suggest that the VITEK 2 system is a suitable tool for a rapid and direct identification and susceptibility testing of Gram-negative rods and Grampositive cocci from blood samples. However, as recommended by Ling et al. and Funke et al. $(13,15)$, the system should be improved for slower metabolic bacteria. The VITEK 2 system error rates are usually based on a comparison with conventional phenotypic methods, which have been reported not to be fully reliable for an accurate identification of bacteria (22).

In other studies the identification of bacteria by the use of molecular biology methods such as FISH and PCR has been shown to be more reliable for the identification of microorganisms in general and also for those responsible for blood infections $(9,23,24)$. Nevertheless the present study results, along with other studies $(10,25)$, indicate that the VITEK 2 system has an overall reliable performance and it is safe enough to allow immediate reporting. It is expected that a major reduction in the time required to determine the correct treatment for patients' infections will lead to reductions in patient mortality and in overall hospital costs (10).

\section{Acknowledgements}

Funding: We would like to thank Philadelphia University, Amman, and Princess Iman Research and Laboratory Sciences Centre, Royal Medical Services, Amman, for their support and cooperation in conducting this research.

Competing interests: None declared. 
References

1. Reimer LG, Wilson ML, Weinstein MP. Update on detection of bacteremia and fungemia. Clin Microbiol Rev. 1997 Jul;10(3):444-65. PMID:9227861

2. Orsini J, Mainardi C, Muzylo E, Karki N, Cohen N, Sakoulas G. Microbiological profile of organisms causing bloodstream infection in critically ill patients. J Clin Med Res. 2012 Dec;4(6):371-7. PMID:23226169

3. Kinane DF, Riggio MP, Walker KF, MacKenzie D, Shearer B. Bacteraemia following periodontal procedures. J Clin Periodontol. 2005 Jul;32(7):708-13. PMID:15966875

4. Peleg AY, Hooper DC, Hooper DC. Hospital-acquired infections due to gram-negative bacteria. N Engl J Med. 2010 May 13;362(19):1804-13. PMID:20463340

5. Maschmeyer G, Noskin GA, Ribaud P, Sepkowitz KA. Changing patterns of infections and antimicrobial susceptibilities. Oncology (Williston Park). 2000 Aug;14(8) Suppl 6:9-16. PMID:10989819

6. Kang Cl, Kim SH, Park WB, Lee KD, Kim HB, Kim EC, et al. Bloodstream infections caused by antibiotic-resistant gram-negative bacilli: risk factors for mortality and impact of inappropriate initial antimicrobial therapy on outcome. Antimicrob Agents Chemother. 2005 Feb;49(2):760-6. PMID:15673761

7. Fitzgibbons LN, Puls DL, Mackay K, Forrest GN. Management of gram-positive coccal bacteremia and hemodialysis. Am J Kidney Dis. 2011 Apr;57(4):624-40. PMID:21333430

8. Chen JR, Lee SY, Yang BH, Lu JJ. Rapid identification and susceptibility testing using the VITEK 2 system using culture fluids from positive BacT/ALERT blood cultures. J Microbiol Immunol Infect. 2008 Jun;41(3):259-64. PMID:18629422

9. Wellinghausen N, Bartel M, Essig A, Poppert S. Rapid identification of clinically relevant Enterococcus species by fluorescence in situ hybridization. J Clin Microbiol. 2007 Oct;45(10):3424-6. PMID:17670922

10. Quesada MD, Giménez M, Molinos S, Fernández G, Sánchez MD, Rivelo R, et al. Performance of VITEK-2 Compact and overnight MicroScan panels for direct identification and susceptibility testing of Gram-negative bacilli from positive FAN BacT/ALERT blood culture bottles. Clin Microbiol Infect. 2010 Feb;16(2):137-40. PMID:19778301

11. Tsalik EL, Jones D, Nicholson B, Waring L, Liesenfeld O, Park $\mathrm{LP}$, et al. Multiplex PCR to diagnose bloodstream infections in patients admitted from the emergency department with sepsis. J Clin Microbiol. 2010 Jan;48(1):26-33. PMID:19846634

12. Jordana-Lluch E, Carolan HE, Giménez M, Sampath R, Ecker DJ, Quesada MD, et al. Rapid diagnosis of bloodstream infections with PCR followed by mass spectrometry. PLoS One. 2013;8(4):e62108. PMID:23626775

13. Funke G, Monnet D, deBernardis C, von Graevenitz A, Freney J. Evaluation of the VITEK 2 system for rapid identification of medically relevant gram-negative rods. J Clin Microbiol. 1998 Jul;36(7):1948-52. PMID:9650942
14. Lupetti A, Barnini S, Castagna B, Capria AL, Nibbering PH. Rapid identification and antimicrobial susceptibility profiling of Gram-positive cocci in blood cultures with the Vitek 2 system. Eur J Clin Microbiol Infect Dis. 2010 Jan;29(1):89-95. PMID:19902279

15. Ling TK, Liu ZK, Cheng AF. Evaluation of the VITEK 2 system for rapid direct identification and susceptibility testing of Gramnegative bacilli from positive blood cultures. J Clin Microbiol. 2003 Oct;41(10):4705-7. PMID:14532207

16. Bruins MJ, Bloembergen P, Ruijs GJ, Wolfhagen MJ. Identification and susceptibility testing of Enterobacteriaceae and Pseudomonas aeruginosa by direct inoculation from positive BACTEC blood culture bottles into Vitek 2. J Clin Microbiol. 2004 Jan;42(1):7-11. PMID:14715724

17. Ligozzi M, Bernini C, Bonora MG, De Fatima M, Zuliani J, Fontana R. Evaluation of the VITEK 2 system for identification and antimicrobial susceptibility testing of medically relevant gram-positive cocci. J Clin Microbiol. 2002 May;40(5):1681-6. PMID:11980942

18. Funke G, Funke-Kissling P. Performance of the new VITEK 2 GP card for identification of medically relevant Gram-positive cocci in a routine clinical laboratory. J Clin Microbiol. 2005 Jan;43(1):84-8. PMID:15634954

19. de Cueto M, Ceballos E, Martinez-Martinez L, Perea EJ, Pascual A. Use of positive blood cultures for direct identification and susceptibility testing with the vitek 2 system. J Clin Microbiol. 2004 Aug;42(8):3734-8. PMID:15297523

20. Hansen DS, Jensen AG, Nørskov-Lauritsen N, Skov R, Bruun B. Direct identification and susceptibility testing of enteric bacilli from positive blood cultures using VITEK (GNI+/GNS-GA). Clin Microbiol Infect. 2002 Jan;8(1):38-44. PMID:11906499

21. Murray PR, Baron EJ, Pfaller MA, Tenover FC, Yolken RH. Manual of clinical microbiology. Washington (DC): American Society for Microbiology Press; 1999.

22. Towner KJ, Cockayne A. Molecular methods for microbial identification and typing. London: Chapman and Hall; 1999.

23. Bosshard PP, Zbinden R, Abels S, Böddinghaus B, Altwegg M, Böttger EC. 16S rRNA gene sequencing versus the API $20 \mathrm{NE}$ system and the VITEK 2 ID-GNB card for identification of nonfermenting Gram-negative bacteria in the clinical laboratory. J Clin Microbiol. 2006 Apr;44(4):1359-66. PMID:16597863

24. Kaleta EJ, Clark AE, Johnson DR, Gamage DC, Wysocki VH, Cherkaoui A, et al. Use of PCR coupled with electrospray ionization mass spectrometry for rapid identification of bacterial and yeast bloodstream pathogens from blood culture bottles. J Clin Microbiol. 2011 Jan;49(1):345-53. PMID:21048006

25. Spanu T, Sanguinetti M, Ciccaglione D, D'Inzeo T, Romano $\mathrm{L}$, Leone $\mathrm{F}$, et al. Use of the VITEK 2 system for rapid identification of clinical isolates of Staphylococci from bloodstream infections. J Clin Microbiol. 2003 Sep;41(9):4259-63. PMID:12958254 